\title{
MOOCs Lack Interactivity and Collaborativeness: Evaluating MOOC Platforms
}

\author{
https://doi.org/10.3991/ijep.v10i2.11886 \\ Dilrukshi Gamage ( $\left.{ }^{凶}\right)$, Indika Perera, Shantha Fernando \\ University of Moratuwa, Moratuwa, Sri Lanka \\ dilrukshi.gamage.1k@ieee.org
}

\begin{abstract}
Massive open online courses (MOOCs) have considered to being a potential to disseminate engineering education at scale. However, the pedagogical requirement demanded engineering student to equip with specific skill sets such as communication, interactivity and collaboration. Yet, MOOCs are skeptical of facilitating those skills. Generally, MOOCs evaluated against accessibility and usability. These evaluations may not perceive whether the platform designs in MOOCs supports to much needed interactions and collaboration required in engineering education. We evaluated 6 MOOC platform designs under the lens of collaboration and types of interactions which occur as learner to learner, learner to instructor, learner to platform and learner to content. Evaluation criteria were derived using previous frameworks and evaluations were conducted using 10 participants. Based on each criteria a matrix was formed with a weight to compare results. We found overall collaboration opportunities in platforms are significantly less than the opportunities to interact. Based on the findings we provide 5 design recommendations and provide a future direction for MOOC platform designs which enables facilitation to engineering education through MOOCs.
\end{abstract}

Keywords-MOOC, interactivity, collaboration, evaluation

\section{$1 \quad$ Introduction}

Engineering pedagogy has been identified as an important concept in order to train students who required to have abilities in accomplishing social communicative processors in building next generation structures and services. Typically, to practice these didacts, engineering education institutions utilized qualified teachers to train demanding engineering education. These teachers are required to train students to be able to have many skills including self-regulation and communicative, collaborative skills [46]. To reduce the skill gap at scale, organizations and institutions promote towards lifelong learning continuity and online learning has been a solution. Online learning technologies such as Massive Open Online Courses (MOOCs) were hyped due to this demand. Since 2012, the introduction of MOOC platforms such as Coursera, edX and Udacity, it was anticipated to become next wave of university learning. However, many of the students who enroll to MOOCs did not complete the courses lead to 
higher dropout rates. Therefore, the researchers were skeptical of the technology used to teach engineering education and raised concerns about the MOOCs on pedagogical point of view [4, 38], accessibility point of view [30] and usability point of view [42]. Yet, attrition, remains a major concern for such platforms [6], remains largely unaddressed by these pursuits [17].

To cater to demanding skills of a next generation engineer, MOOCs need to meet its quality standards. According to many research, quality of a MOOC heavily relied on dimensions such as Interactivity and Collaboration as elements in MOOC platforms [3, 28]. In order to cater the skills demanded from an engineering student, MOOCs are required to facilitate Interactivity and Collaboration in its platform design. However, MOOCs completion rates are at risk unless the MOOCs re-consider its platform design to cater interactivity and collaboration. To obtain the current state of the interactivity and collaboration dimensions in MOOC platform designs and to provide empirical evidence of its absence or minimal presence, we conducted this research which evaluate MOOC platforms under the lens of Interactivity and Collaboatativenes. Therefore, our main research questions are:

- Are MOOC platforms facilitating Interactivity in the platform to cater the demanded engineering skills?

- Are MOOC platforms facilitating Collaborations in the platform to cater the demanded engineering skills?

- If they are not meeting Interactivity and Collaboration, how do we re-think the models and design for these platforms in future to meet the engineering skills?

In this paper, we explain the criteria for evaluating MOOC platform design and walk through the evaluation of 6 MOOC platforms. Results explain the gaps in the designs, thereby we provide key recommendations to improve interactivity and collaboratives. We envision, in future, platform designers and instructional designers for MOOC will incorporate these findings and increase the learners experience and satisfaction and reduce the attrition while importantly facilitating to disseminate engineering skills for wider audience.

\section{Literature Review}

\subsection{Engineering pedagogy and MOOCs}

Researchers review the potentials MOOCs being a facilitator for disseminating engineering education. Engineering education has been identified as teaching the students on the practical knowledge and skills needed in the field of Engineering. The subjects offered in MOOCs relating to engineering expand in pure theoretical foundations to practical knowledge such as Liner Algebra, statistics and robotics but not limited to those [47]. Although the potential of MOOCs for engineering education is depicted [47], researchers yet highlight many problems including the challenges of MOOCs of not been interactive enough and not providing collaborative opportunities $[47,48]$. 


\subsection{Background to MOOCs}

MOOCs originated with the Connectivism and Connective Knowledge MOOC provided by University of Manitoba in 2008 [19], but the introduction of Coursera, edX and Udacity MOOC platforms in 2012 led a significant trend [29]. There are two types of MOOCs, distinguished by their pedagogy. cMOOC follow a "connectivism" pedagogy where there are no well-defined instructions to follow in content yet people connecting to cMOOC decide the focus areas $[5,23]$ and xMOOC follow an "instructivist" pedagogy with well-defined instructions for short term, structured learning and outcomes $[11,36]$. However, xMOOCs are different as they were initiated through platforms like Coursera, edX and Udacity. This difference is important in this context as cMOOCs are often found to be based on learner-learner interactions and collaborating and co-creating content while not sticking to a particular learning platform. Our focus in the research is on XMOOCs, which affords less interactivity and collaboration between users where platforms leverage open enrolled courses and the course pedagogy follows a similar structure with in the platform. The courses are entirely based on infrastructure provided by the platform and the content is mostly disseminated via short chunks of video, and evaluated via short quizzes. xMOOCs are assessed by self/peer grading or automated grading and generally support discussions among participants via forums. The latest meta review of the MOOCs indicate that the research and development for MOOCs have been focusing on 1) the potential and challenges of MOOCs for universities; 2) MOOC platforms; 3) learners and content in MOOCs; and 4) the quality of MOOCs and instructional design issues [43]

\subsection{Evaluating MOOCs}

Although MOOCs were offered free, since 2015 these models have shifted to require payment for completion certificates, or in some cases, to see any content. However, with these changes, there has not been change in the pedagogy which concerned and raised skepticisms [35]. A common problem for MOOCs is attrition and explorations mainly focused in this direction. Researchers found lack of time, lack of engagement. Interactions as key reasons $[2,24]$ for attrition and many of studies provide predictive modeling techniques to identify drop outs $[18,31,39]$. Other studies found that bad time managements skill of students lead to drop outs and suggested that platforms should not only provide their users with high quality educational materials with interaction but platforms should design to support uplift skills of the user [25]. Thus, they urge MOOCs should provide tools helping to optimize time usage, selfregulation and subsequently develop meta cognition skills indispensable for proper time management of learning processes. Onah and Sinclair, in their research evaluated self-regulated learning (SRL) and explored the various existing dimensions used to expose the learners SRL skills. They found that, MOOCs success required a high performance of self-regulated learning abilities which at the moment very little supporting SRL skills in platforms. They conducted an online self-regulated learning questionnaire (OSLQ) as the instrument to measure the SRL skills [27]. Its predictions are based on usage of existing platform features. It is important to understand 
design features of MOOCs platforms which may affect the quality of a course. However, less attention has been given to evaluate existing MOOC platform designs.

\subsection{MOOC evaluation criteria and tools}

Evaluation of MOOCs has been conducted, independent of the platform used to deliver the course. The majority of these evaluations were based upon instructional quality [20], pedagogical design [4] and general strategies and implementing of MOOCs [21]. However, the number of MOOC platforms are increasing with the number of courses. Since MOOC is a new phenomenon, criteria to evaluate MOOCs was not properly established. Therefore, many of MOOCs were evaluated using conceptual theories [26] and frameworks that have used to evaluate eLearning but not MOOCs specifically $[9,13]$. Researchers argue that evaluating MOOCs using tools built for eLearning may not capture the real outcome of expectations of MOOCs [10]. The majority of existing tools for evaluating MOOCs focus on pedagogy, instructional design, and usability [14], and not the broader design implications.

We highlight two tools which provide criteria to evaluate a course in a MOOC platform. These tools were empirically tested and validated to evaluate than many other conceptual frameworks. First tool consists of criteria of:

- User interface

- Assessment

- Video content

- Learning

- Social engagement

- Instructional design [41].

Second tool has 10-dimensional framework which describe:

- Interaction

- Collaboration

- Motivation

- Network of opportunities and future directions

- Pedagogy

- Content

- Assessment

- Usability

- Technology

- Support for learners [13].

However, two of these tools focus on to evaluating the success of a course in a MOOC platform specifically. Although, not all factors were relevant to our research, factors of Interactivity and Collaboration criteria is in our interest to this research. However, in our study, we focus on evaluation of the MOOC platforms design specifically, rather than the course. Since the courses are built using the platform design, overall success of MOOC mostly dependent on how the platform support by its de- 
sign. Yet, previous research work on evaluating platforms designs for MOOCs were based on Accessible need [15] and Usability [42]. There's a lack of exploration in assessing the MOOC platform designs systematically to foresee the gaps in designs that need to facilitate in order to deliver a quality MOOC.

\section{Evaluation of MOOC Platform Designs}

Interactivity and Collaboration in a MOOC is identified as student's success factors in many research works $[13,41]$. In order to evaluate the MOOC platform designs, we are required to select number of MOOC platforms and an evaluation criterion. Rather than exploring the accessibility compliances or usability which previously has conducted, our focus in the platform's designs were based on unique measures of:

- Interactions

- Collaboration.

Authors utilized previously developed framework which has criteria to evaluate against Interactivity and Collaboration [49]. This framework had 10 dimensions including the details of items to evaluate Interactivity and Collaboration and it was empirically tested for reliability and validity to provide accurate information. Explaining the detail 10-dimensional framework is beyond this research and due to limited space, we explain only the direct criteria relating Interactivity and Collaborations. For more details of the entire framework, we have revealed the project details and surveys used in the criteria selection in open repository [50].

Following heuristics explain the derived Interactivity and Collaboration criteria from this framework which examined against the MOOC platform:

Learner - Learner interaction: Is there a Forum to interact, is the forum support multiple data files, links and multimedia, profile with direct messaging for communication interactivity, peer availability indicator and instant chat in the platform.

Learner - Instructor interaction: Forum thread reply to instructor by participant, assignment submission feedback as a thread and direct message to the instructor.

Learner - Platform interactions: Course progress interactions, Course certificates, system help or support, verification support, personalized course dash board with recommendations, current courses and pass courses.

Learner - Content interactions: Short video content, Peer reviewed assignment, quizzes to mater base learning, other content type to consume such as pdf files or links to other web or wiki pages, participants are co-creators of the content.

Platform collaborativeness for users: Evaluating collaboration is to understand whether platforms designs facilitate group engagements. Collaboration evaluated against in terms of platform support to form groups, communicate in groups, work in groups and meet in a group. 


\subsection{Selecting sample}

Since 2011, there have been many MOOCs offered, from more than 700 universities around the world, and there are 58 million students who had signed up for at least one MOOC [33]. Many countries around the world (e.g. India, Mexico, Thailand, Italy, and more) have launched their own country-specific MOOC platforms. This describes the population relevant to this research. Deriving a sample to our research was conducted based on the facts provided by a MOOC aggregating system. MOOC aggregating system is a platform which keeps MOOCs records of all of the MOOC platforms such as number of users, number of courses. Although there are few MOOC aggregating systems, which keeps track of number of users, course and subjects, we consider 2 major systems based on the size of data. They are Class Central and MOOC Lab. According to these aggregating platforms, there are about 30-58 MOOC platforms. A systematic sample [1] was derived based on Location of platform the which determines language and criteria such as Number of Users, Number of Courses, Subjects, Certificates, language etc. We filtered platforms based on the highest user base, largest number of courses, and eliminated any non-English base languages due to the language barrier to explore the platform. With this filter, 6 platforms were selected for analysis:

- Coursera

- $\mathrm{EdX}$

- Future Learn

- OpenSAP

- Open Learning

- Iversity.

\subsection{Method}

Our research contribution to explore the interactivity and collaboration in MOOC platforms were conducted and tested empirically recruiting 10 experienced participants to evaluate the platforms. They were recruited using snowball method and experience was filtered based on prior knowledge on designing developing platforms and instructional design. Out of 10 evaluators, 4 of them are females and 6 of them were males. All were between 25-40 years of age and out of those 6 are professionally work in organizations as daytime job and 4 work as freelancers. They observed and examined the anatomy of platform designs by enrolling to courses in each MOOC platform for a period of 8 weeks leaving enough time to observe platform.

We explored mechanisms to identify interactivity and collaboration features with thresholds and as a best method, created a matrix using the framework and weighted the highest support from the platform design as 3, medium as 2 and low as 1 and no support from the platform as 0. For example, Observer 1, will enroll the Platform Cousera and examine if there is a forum support compliance with leaner to leaner interaction and if it is fully complied, this will be weighted in a matrix as 3. Comparing heuristics with the use of a matrix is one method of objectively evaluating a num- 
ber of options against a number of criteria. We avoided the selection and rating bias, since there 10 evaluators. They were carefully observing and evaluated each platform designs while enrolling to courses in those platforms. We finally used the average values of evaluation results. The inter-rater reliability Cohen's kappa 0.81 provided evidence with substantial agreement between the rating of these platforms by the evaluators.

\subsection{Evaluating the interactivity in the platforms}

Although there is no well-defined definition of interactivity in MOOC platforms, through background research we identified it is mainly how participants engage with the platform, content and other stakeholders. The evaluators examine each interaction type out of identified 4 types against the selected 6 platforms according to the framework and criteria derived $[49,50]$ to this research as:

Learner-learner interaction: Learner-learner interaction is how the platform affords interacting with other learners. The most common interaction method was the forum where they were able to reply or start new discussion as an interaction. Even in the forum, the features support to learner-learner interactions may vary. We identified each platform has designs to facilitate these interactions, but some platforms were designed such that it provided less features to interact with other learners. As we examined, some forums allowed any space, insert graphics, attachments or links. Yet we observed, Future learn platform design allowed only 1200 characters threshold for the interaction. However, some platforms are designed such that it allowed to send direct messages to peers in case if they need any clarification. Some platforms redirected forums to other third-party platforms such as "Discourse" which allowed to send direct messages to participants. Profile pages of participants were commonly facilitated with this feature, yet again we observed Future Learn platform allowed only to follow the interested participant on how they reply to comments barring direct communications. Coursera, OpenSAP and edX lead to blank state of profiles leaving no further interactions. Instant chat is a latest feature we observed in the platform which indicate who are the users online at an instance.

Learner-content interaction: Interaction plays a critical role in the learning process. Thus, for MOOC participants, other than the learner-learner engagement, interaction with the course content (learner-content interaction) is especially important because it can contribute to successful learning outcomes and course completion. The relationship between learner-content interaction and course grade to determine if this interaction type is a contributing success factor and found significant positive affect to learning in interacting with content [12]. Data related to student interaction with course content, including time spent reviewing online course materials, such as short videos of the course, taking assignments, reading other related links PDF's and attachments provided by the course and time spent completing weekly quizzes, were identified as main type of interactions [45].

The derived evaluation criteria indicated to examine content against whether it is updated, user friendly and relevance. However, when examining a platform design, we identified it is more relevant to check how platforms let users to interact with its 
course content. The central location for course content is the course dashboard in a platform. We examined course dashboard of 6 platforms to identify whether platform designs are facilitating features of content display, content forms such as short video, web links, PDF and other sort of attachments, tools and apps. At the same time, some platforms allowed participants to interact with content in the means of answering to quizzes and submitting assignments. We also considered if the participants were given the opportunity to co-create content as web 2.0. It has found that when including the learner as part of the course team from an early stage, leads to richer learning sequences and has made more richer engaging experience.

We present the content interaction variations in the form of features in the platform's designs. A dash boards in platforms highlight its display of content clearly indicating video, quiz, other link, reading material and in different way to indicate the progress of individual interactions in the content. We observe the content usage of the course in the form of weekly progress and course progress which indicated in the course dashboard. The Future Learn platform had a manual interaction by the user to indicate the progress of the content. We highlight this difference in Fig. 1, which has a purple indicated button for unread materials as "Mark as read" and once the user clicked, it converts to different color code and will be accumulate to the progress of the course. This interaction is automatic in the other platforms as when user browse through courses materials.

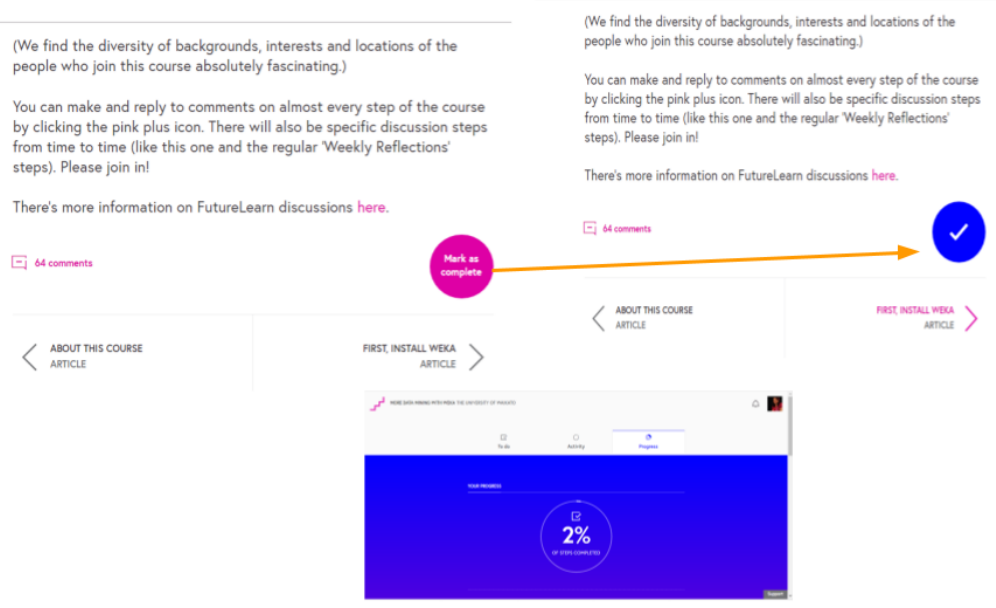

Fig. 1. Future Learn platform offers manual update on the course progress

We observed that there is no particular design in a platform to co-create content using students yet co-creating content is practiced in a special course "adelaidex bard101x" in edX platform from Adelaide University. In this course instructors used few students into designing the course yet it is an internal decision by the university. The platform design does not contain a feature to co-create content with students. However, the overall evaluation in content interactions revealed all the MOOC platforms in our sample comply with the content interaction criteria. 
Learner-system iteration: This type of interactions describes as how users use the platform provider as a tool to learn. Mainly apart from course dashboard which much relevant in content interactions, the system dashboard to support students monitor courses in terms of completion, certificates, verification steps, recommended courses based on individual interest and student support in the system. Since a dashboard found to be the key point to produce information and direction, resulting experience in a dashboard interaction will lead to student's motivation. Our observations in the platforms resulted similar features to all the platforms. As example it contained direct system support features for student interactions, search course and course recommendations, current courses, completed course etc.

Learner-instructor interaction: Learner-instructor interaction is explained as in the tool as how instructor's engagement and provide feedback to students in a MOOC. We evaluated whether platforms contain designs features where instructors given opportunity to interact with participants in the platform design. We found two designs which allowed students to interact with instructors: forum and in special cases assignment submission. Platform designs support to distinguish when instructors reply to a thread. Yet none of the MOOC platforms provided direct interaction feature to participant in interacting with the instructor. Typically, we observed the MOOC platform design model does not particularly facilitate to interact directly with the instructor. Thus, it was clear that instructor was expected mostly to provide content to the platform and not engage further directly. Research work revealed students perceived instructor interaction as a top requirement, yet instructors are satisfied with the existing design claiming the infeasibility of catering to individuals in a massive enrollment [17]. The MOOC model itself is identified as "Instructivisits" approach due the design of MOOC platform which place instructor's role as a course creator. Participants were facilitated in the platform to consume the content created by instructors but not with the instructor directly. At the same time, Instructor to learner interaction were mainly seen in the emails sent and course update notices.

\subsection{Evaluating the collaborations in the platforms}

Collaborativeness in a MOOC platform is how students engage in activities as a group. This requires effective communication facilitates. Many researchers claim MOOCs are lack of collaboration $[8,37]$, yet in this examination we aim to identify systematically on platform deigns. We observe whether the platform provide facility to create a group or join groups, provide communication tools to the group synchronous and asynchronous, provide a work space, provide facilities to submit group artifacts and tools to schedule meeting times. Out of 6 evaluated platforms, we found Coursera, edX, Future Learn and Iversity offered highly limited collaborative opportunities. All 4 platforms provided the forum as the only collaboration space in the platform design. However, as evaluators enrolled to many courses, some of the courses incorporated external platforms in for synchronous communications such as Google hangouts or provided live YouTube link where participants can chat. Yet it was not structured as in the platform. The only possibility to initiate in forming a group is posting in the form as platforms did not contain a feature supporting. 
At the same time mostly, the platform facilitates only single submissions in the assignments discouraging the collaborative submissions. However, extensive design features found in OpenSAP and Open learning platforms providing wide range of tools to support collaboration with in the platform. The OpenSAP platform some courses are pedagogically designed to lead with groups yet some courses do not require to complete with a group. OpenSAP "Collab Spaces" tab lead the space where groups can collaborate. "Collab Space" leads to either to create individual groups collaborate to open groups or close groups. The user can join to any open group in a straight click or request to join in a close group where the group will verify whether to accepted or not. The group space inside the "Collab Spaces" provides features where group can view recent activities in the group, discuss among members in a private thread to the group, Collaborative writing tool and also facilitate to make a group call using Google Hangout tool.

The Open Learning MOOC platform facilitate the group collaboration with features similar to OpenSAP by allowing participants to create open or close groups. However, the difference of the Open Leaning platform group space is that it provides the flexibility for the group leader or the administrators to arrange the layout of the group using the widgets. These widgets include with group space, conference call, social media tools within the groups. The conference call in the group is supported by an opensource web conferencing tool. Many of the supporting tools in the platform will aid to increase the accessibility to the participants where they can be collaborating with various means and serve in the group.

\section{$4 \quad$ Evaluation Results and Discussion}

\subsection{MOOC platforms lack interactivity- RQ1}

To test the Interactivity in the platforms we present the matrix after evaluating the criteria as depicted in Fig. 2. We explained our strategy of using 10 evaluators, according to heuristics provided in the method section, highest compliance of heuristic is given 3 and 2, 10 respectively for medium, low and not meeting. Average evaluation value from 10 participants were taken in the matrix. The results of the matrix depict that platform designs most supported towards learners' interaction to content and less attention given to build designs which support learner-learners and learners to Instructor interactions. At the same time comparing among the platforms only Open Learning and OpenSAP provide the highest interactivity featured enabled platforms.

\subsection{MOOC platforms lack collaboration- RQ2}

Evaluation results of the dimension collaborativeness in the form of matrix is presented in Fig. 3. Highest collaborative featured platform design identified as OpenSAP and Open Learning platforms yet other 4 platform designs did not support collaboration at all. Research suggest platforms require to direct designs which enable social structures thereby impact the attrition in MOOCs while motivating students 
[32]. Yet, this revealed that the platform design space lacked to support collaboration as depicted in Fig. 3.

\begin{tabular}{|l|l|l|l|l|l|l|}
\hline Platforms Learner System Interactivity & $\mathbf{1}$ & $\mathbf{2}$ & $\mathbf{3}$ & $\mathbf{4}$ & $\mathbf{5}$ & $\mathbf{6}$ \\
\hline Course progress interactions & & & & & & \\
\hline Course certificates & & & & & & \\
\hline System help / support & & & & & & \\
\hline Verification support & & & & & \\
\hline $\begin{array}{l}\text { Personalise Course Dashboard/ recommendation, current } \\
\text { courses , past courses }\end{array}$ & & & & & & \\
\hline
\end{tabular}

Platforms

1. Coursera

2. edX

3. FutureLearn

4. Iversity

5. OpenSAP

6. OpenLearning

Support

\begin{tabular}{|l|l|l|l|l|l|l|}
\hline Platforms Learner Instructor Interactivity & $\mathbf{1}$ & $\mathbf{2}$ & $\mathbf{3}$ & $\mathbf{4}$ & $\mathbf{5}$ & $\mathbf{6}$ \\
\hline Forum thread reply to Instructor by participant & & & & & & \\
\hline Assignment submission feedback discussion as thread & & & & & & \\
\hline Direct message to instructor & & & & & \\
\hline
\end{tabular}

High

Medium

Low

No

\begin{tabular}{|l|l|l|l|l|l|l|}
\hline Platforms Learner Learner Interactivity & $\mathbf{1}$ & $\mathbf{2}$ & $\mathbf{3}$ & $\mathbf{4}$ & $\mathbf{5}$ & $\mathbf{6}$ \\
\hline Foum to interact & & & & & & \\
\hline Forum support multiple data such as links, multimedia & & & & & & \\
\hline Profile page with messaging direct communication & & & & & \\
\hline Peer Availability indicator & & & & & \\
\hline Instant chat & & & & & \\
\hline
\end{tabular}

Platforms

1. Coursera

2. edX

3. FutureLearn

4. Iversity

5. OpenSAP

6. OpenLearning

\section{Support}

\begin{tabular}{|l|l|l|l|l|l|l|}
\hline Platforms Learner Content Interactivity & $\mathbf{1}$ & $\mathbf{2}$ & $\mathbf{3}$ & $\mathbf{4}$ & $\mathbf{5}$ & $\mathbf{6}$ \\
\hline Short video content & & & & & \\
\hline Peer Reviewed Assignment & & & & & \\
\hline Quizzes as master base learning & & & & & \\
\hline Other Content types to consume PDF, Web, Links & & & & & & \\
\hline Participants as co-creators of content & & & & & & \\
\hline
\end{tabular}

Fig. 2. Evaluation Matrix in Interactions ( L-L, L-C, L-S, L-I) 

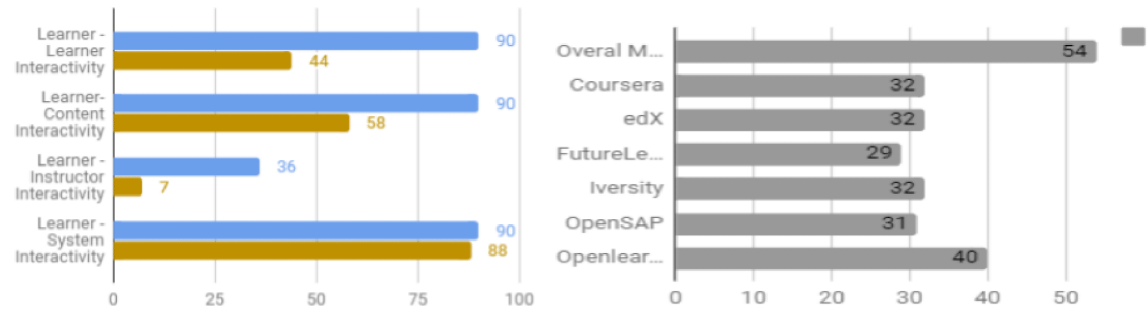

a. Interactivity support by Platforms

b. Expected Interactivity vs Support by each platform

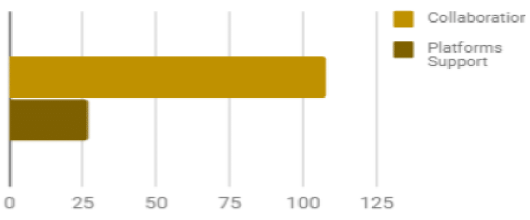

C. Collaborativeness in Platforms

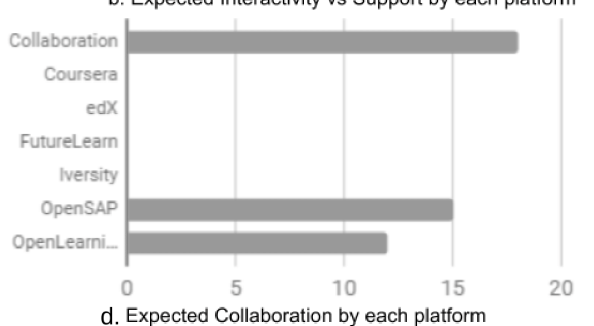

Fig. 3. Overall collaboration and Interactivity measurements: a) Blue bar indicate the best case of interactivity in 6 platforms (i, e for learner to learner interactivity 30x3) and brown indicate the measurement through evaluation in the matrix. b) Top bar is the benchmark for expected interactivity and each platforms interactivity level is indicated in below bars. C) Similar to Interactivity, Collaboration matrix has the expected and evaluators has indicated the level which supported- this indicate collaboration is always at very low than expected. d) Explains the expected Collaboration level, and how much supported by each platform in comparison to 6 platforms we observed.

\subsection{Recommendation and future direction to platform design platforms- rq3}

As required skills for engineering students, it is essential that engineering pedagogy reflect interactivity and collaborativeness in to their instructional design. In MOOCs which has been a potential to disseminate the engineering education found to be lacking these criteria. Specially, when identifying the criteria for a successful and quality MOOC, we found many platforms do not comply with the learner's expectations in Interactivity and Collaboration. Platforms mostly been concentrated to meet the quality in system interactions with students and providing interaction in the content. They have neglected intervention which will increase the interaction among other learners individually and as a collaborative group. At the same time, system is designed such that it kept instructors out of interaction with students, but research found that instructors direct input has valued higher in students perspective [17]. According to Kefalis and Drigas [16], when users can access knowledge through distance in formal or informal environment of MOOCs with Web 2.0 tools, the communication between learners and teachers is being synchronous and promotes collaboration. Since digital labs provide flexibility it was achievable in cognitive level as the same level as other face to face. These eLearning technologies aid teachers and learners access knowledge easy and effective promoting digital literacy. Thus, we provide 
design insights as recommendation for future where platforms and interface designers could think in the years ahead of 21 st century learning.

- R1: Scaffold interaction designs to engage with other learners: Participants in a learning platform may not use the interactions effectively unless the platform design in such a way to make easy connections. Visible profiles with a reputation mechanism will increase the chance of identifying students in a massive environment. Some MOOCs experiment with reputation mechanism in forum Coetzee et al. [7], which increase learning outcome. We envision the potentials of incentive compatible reputation system populate among students which will increase motivation to connect with the matching groups.

- R2: Open collaborative groups and selection of groups based on AI and machine learning During many courses, forming groups has been challenging since the platforms does not much understand the users. Yet many researchers recommend to use groups in MOOCs [22]. Identified behaviors and based on the levels, allowing systems to create and form groups which could best fit in such short time span would be ideal. We bring the reference of creating such creative dream team's where system explores a large space of possible team structures to identify effective structures for each team based on observable feedback [34].

- R3: Designs to support student instructor interaction at scale We highlight on the fact that system is designed where it expects less interactions from instructor. However, learners prefer interactions directly from instructor. Since massive number of enrollments made it impossible for instructor to interact. We recommend designs which enhance the instructor involvement with students while providing tools to communicate. At the same time, we propose a liquid scaling (based on demand) of instructor levels based on the exceptional students which has potential to be teaching assistants and promote into open instructor levels of guilds. System designs which will able to provide small group facilitation with selected leveled instructors promoted within students. In other words, designing mechanisms to uplift potential students to become instructor levels and build a level of guilds such as in crowd guilds [40].

- R4: Designs which support co-create content with students Currently, the platform is designed such that instructors will create the content and publish as a course, leaving participants to be content consumers. We recommend platform designs to incorporate co-created content by students. We envision systems which assign students to build content based on the submissions of the assignments, based on the communication taken place in forum etc. This make students active learners and platform should systemically scale down the massive number of students identifying potential students' groups who can contribute to content.

- R5: System support to scale down massiveness and create open learning communities. Another direction that we foresee is the potential of increase collaboration and interaction using strong open learning communities. Many studies suggest that the relatively weak feelings of community and meager opportunities for collaboration may be contributing to a high dropout rate in MOOCs [44]. It is im- 
portant to explore new design features that could support enhanced social interactions by designing and guiding towards open learn communities of MOOCs.

\section{Conclusion}

Engineering pedagogy is essential to train students who are determined to solve engineering problems, build structures and provide services. One way of teaching engineering to large scale is possibly using MOOC platforms. However, due to many skeptics, it was not sure MOOC platforms facilitating interactivity and collaborativeness where it has been identified as key components to teach the engineering students. This research empirically test the status of platforms in terms of collaborativeness and interactivity by using criteria in a MOOC quality framework. Selected 10 evaluators rated the platform criteria using a matrix. While having substantial inter rater reliability of .81 , the results proved that many MOOC platforms are lacking key required features. Evaluation of MOOCs been concentrating on pedagogy and platform designs have been focusing on accessibility needs. It is important to evaluate ad identify MOOC platform designs from the standpoint of exploring how to support quality MOOC experiences too. The quality of a MOOCs often relies on Interactivity and Collaboration supported in the platform. We selected a sample size of 6 MOOC platforms and evaluated those platforms incorporating criteria derived from MOOC quality frameworks.

Our results concluded that MOOC platforms are high in learner-system interactivity and learner-content interactivity. Learner-learner interactions and learner-instructor are significantly lacking. Overall interactivity in platforms space were only $64 \%$ from expected and only Open learning MOOC platform contributed while being the highest interactivity level platform designs. In terms of Collaboration, platforms supported only $25 \%$ level collaboration yet again OpenSAP and Open to learning platforms provided highest and only collaboration design features in the platform.

\section{$6 \quad$ References}

[1] Altmann.J (1974). Observational study of behavior: sampling methods. Behavior 49, 3 (1974), 227-266. https://doi.org/10.1163/156853974X00534

[2] Amir. Y (2018) Modeling Student Engagement and Attrition in BJCx, a CS Principles MOOC. In Proceedings of the 49th ACM Technical Symposium on Computer Science Education. ACM, 1099-1099. https://doi.org/10.1145/3159450.3162310

[3] Amo. D (2013). MOOCs: experimental approaches for quality in pedagogical and design fundamentals. In Proceedings of the First International Conference on Technological Ecosystem for Enhancing Multiculturality. ACM, 219-223. https://doi.org/10.1145/2536536. 2536570

[4] Bali.M (2014). MOOC pedagogy: gleaning good practice from existing MOOCs. Journal of Online Learning and Teaching 10, 1 (2014), 44.

[5] Blanco A F, García-Peñalvo F J, and Sein-Echaluce.M (2013). A methodology proposal for developing adaptive cMOOC. In Proceedings of the First International Conference on 
Technological Ecosystem for Enhancing Multiculturality. ACM, 553558.https://doi.org/10.1145/2536536.2536621

[6] Clow. D (2013). MOOCs and the funnel of participation. In Proceedings of the Third International Conference on Learning Analytics and Knowledge. ACM, 185-189. https://doi.org/10.1145/2460296.2460332

[7] Coetzee D, Fox A,Hearst M A, and Hartmann. B (2014). Should Your MOOC Forum Use a Reputation System? In Proceedings of the 17th ACM Conference on Computer Supported Cooperative Work \& Social Computing (CSCW '14). ACM, New York, NY, USA, 1176-1187. https://doi.org/10.1145/2531602.2531657

[8] Collazos C A, González C S, and García R. (2014). Computer supported collaborative MOOCs: CSCM. In Proceedings of the 2014 Workshop on Interaction Design in Educational Environments. ACM, 28. https://doi.org/10.1145/2643604.2643629

[9] Conole.G (2016). MOOCs as disruptive technologies: strategies for enhancing the learner experience and quality of MOOCs. RED. Revista de Educación a Distancia 50. https://doi.org/10.6018/red/50/2

[10] Downes S. (2013). The quality of massive open online courses. International Handbook of E-learning 1, 65-77.

[11] Fidalgo-Blanco A, Sein-Echaluce M L, and García-Peñalvo F J. (2016). From massive access to cooperation: lessons learned and proven results of a hybrid xMOOC/cMOOC pedagogical approach to MOOCs. International Journal of Educational Technology in Higher Education 13, 1, 24. https://doi.org/10.1186/s41239-016-0024-z

[12] Gameel B G. (2017). Learner Satisfaction with Massive Open Online Courses. 31,1-14. https://doi.org/10.1080/08923647.2017.1300462

[13] Gamage D, Fernando S, and Perera.I (2015). Quality of MOOCs: A review of literature on effectiveness and quality aspects. In Ubi-Media Computing (UMEDIA), 2015 8th International Conference on. IEEE, 224-229. https://doi.org/10.1109/UMEDIA.2015. $\underline{7297459}$

[14] Gamage D, Perera I, and Fernando S. (2016). Evaluating Effectiveness Of Moocs Using Empirical Tools: Learners Perspective. In Inted 2016 Proceedings (10th International Technology, Education and Development Conference). IATED, 82768284.https://doi.org/10.21125/inted.2016.0937

[15] Iniesto,F , Rodrigo F, and Teixeira M A. (2014). Accessibility analysis in MOOC platforms. A case study: UNED COMA and UAbiMOOC2014.

[16] Kefalis C and Drigas A. (2019) Web Based and Online Applications in STEM Education. International Journal of Engineering Pedagogy (iJEP) 9, 4 (2019), 7685.https://doi.org/10.3991/ijep.v9i4.10691

[17] Khalil H and Ebner M. (2013). âĂIJHow satisfied are you with your MOOC?âĂİ-A Research Study on Interaction in Huge Online Courses. In EdMedia:World Conference on Educational Media and Technology. Association for the Advancement of Computing in Education (AACE), 830-839. ACM Trans. Comput.-Hum. Interact., Vol. 11, No. 1

[18] Lu X, Wang, S, Huang J, Chen W, and Yan A. (2017). What Decides the Dropout in MOOCs? In International Conference on Database Systems for Advanced Applications. Springer, 316-327. https://doi.org/10.1007/978-3-319-55705-2_25

[19] Mackness J, Mak S, and Williams R. (2010). The ideals and reality of participating in a MOOC. In Proceedings of the 7th International Conference on Networked Learning 2010. University of Lancaster.

[20] Margaryan A, Bianco M, and Littlejohn A. (2015). Instructional quality of massive open online courses (MOOCs). Computers \& Education 80 (2015), 77-83. https://doi.org/10.10 $\underline{\text { 16/j.compedu.2014.08.005 }}$ 
[21] Marshall S. (2013). Evaluating the strategic and leadership challenges of MOOCs. Journal of Online Learning and Teaching 9, 2 (2013), 216.

[22] Mayende G, Prinz A, Isabwe G M N, and Muyinda P B. (2017). Learning Groups in MOOCs Lessons for Online Learning in Higher Education. International Journal of Engineering Pedagogy 7, 2 (2017), 109-124. https://doi.org/10.3991/ijep.v7i2.6925

[23] Milligan C, Littlejohn A, and Margaryan.A (2013). Patterns of engagement in connectivist MOOCs. Journal of Online Learning and Teaching 9, 2 (2013), 149.

[24] Nagrecha S, Dillon J Z, and Chawla N V. (2017). MOOC dropout prediction: lessons learned from making pipelines interpretable. In Proceedings of the 26th International Conference on World Wide Web Companion. International World Wide Web Conferences Steering Committee, 351-359. https://doi.org/10.1145/3041021.3054162

[25] Nawrot I and Doucet A. (2014). Building Engagement for MOOC Students: Introducing Support for Time Management on Online Learning Platforms. In Proceedings of the 23rd International Conference on World Wide Web (WWW '14 Companion). ACM, New York, NY, USA, 1077-1082. https://doi.org/10.1145/2567948.2580054

[26] Nkuyubwatsi B. (2013). Evaluation of massive open online courses (MOOCs) from the learner's perspective. In European Conference on e-Learning. Academic Conferences International Limited, 340.

[27] Onah D and Sinclair. J (2017). Assessing self-regulation of learning dimensions in a standalone MOOC platform. International Journal of Engineering Pedagogy 7, 2, 4-21. https://doi.org/10.3991/ijep.v7i2.6511

[28] Ossiannilsson E, Altinay F, and Altinay Z. (2015). Analysis of MOOCs practices from the perspective of learner experiences and quality culture. Educational Media International 52, 4, 272-283. https://doi.org/10.1080/09523987.2015.1125985

[29] Pappano. L (2012). The Year of the MOOC. The New York Times 2, 12 (2012),

[30] Ramírez-Vega A, Iniesto F, and Rodrigo C. (2017). Raising Awareness of the Accessibility Challenges in Mathematics MOOCs. In Proceedings of the 5th International Conference on Technological Ecosystems for Enhancing Multiculturality (TEEM 2017). ACM, New York, NY, USA, Article 92, 8 pages. https://doi.org/10.1145/3144826.3145435

[31] Rizzardini R H and Amado-Salvatierra.H (2017). Full Engagement Educational Framework: A Practical Experience for a MicroMaster. In Proceedings of the Fourth ACM Conference on Learning @ Scale (L@S '17). ACM, New York, NY, USA, 145-146. https://doi.org/10.1145/3051457.3053969

[32] Rosé C P, Carlson R, Yang D, Wen M, Resnick L Goldman P, and Sherer J. 2014. Social factors that contribute to attrition in MOOCs. In Proceedings of the first ACM conference on Learning@ scale conference. ACM, 197-198. https://doi.org/10.1145/2556325. 2567879

[33] Sharh D. [n. d.]. By the Numbers: MOOCS in 2017. ([n. d.]).

[34] Bernstein M S, Zhou S, Valentine M (2017). In Search of the Dream Team: Temporally Constrained Multi-Armed Bandits for Identifying Effective Team Structures. In Proceedings of the 2017 CHI Conference on Human Factors in Computing Systems.

[35] Siemens G, Dillenbourg P, Fischer G, McNamara D, and Rummel N. (2014). Where are the Learning Sciences in the MOOC Debate? In Learning and Becoming in Practice: 11th International Conference of the Learning Sciences (ICLS), Boulder. 15-17.

[36] Skrypnyk,O, JoksimovicìĄ S, KovanovicìĄ V, GasìŇevicìĄ D, and Dawson S. (2015). Roles of course facilitators, learners, and technology in the flow of information of a cMOOC. The International Review of Research in Open and Distributed Learning 16, 3. https://doi.org/10.19173/irrodl.v16i3.2170 
[37] Staubitz, T, Pfeiffer T, Renz J, Willems C, and Meinel C. (2015). Collaborative learning in a MOOC environment. In Proceedings of the 8 th annual international conference of education, research and innovation. 8237-8246.

[38] Swan K, Day S, and Bogle L. (2016). Metaphors for Learning and MOOC Pedagogies. In Proceedings of the Third (2016) ACM Conference on Learning@ Scale (L@S '16). ACM, New York, NY, USA, 125-128. https://doi.org/10.1145/2876034.2893385

[39] Whitehill J, Mohan K, Seaton C, Rosen Y, and Tingley D. (2017) MOOC Dropout Prediction: How to Measure Accuracy? In Proceedings of the Fourth (2017) ACM Conference on Learning@Scale. ACM, 161-164. https://doi.org/10.1145/3051457.3053974

[40] Whiting M E, Gamage D, Gaikwad S N, Gilbee A, Goyal S, Ballav A, Majeti D, Chhibber N, Richmond-Fuller A, Sarma T S , Chandrakanthan V, Moura T, Salih M S, Kalejaiye G T, Ginzberg A, Mullings C A, DayanY, Milland K, Orefice H, Regino J, Parsi S, Mainali K, Sehgal V, Matin S, Sinha A, Vaish R, and Bernstein M S . (2017). Crowd Guilds: Worker-led Reputation and Feedback on Crowdsourcing Platforms. In Proceedings of the 2017 ACM Conference on Computer Supported Cooperative Work and Social Computing (CSCW '17). ACM, New York, NY, USA, 1902-1913. https://doi.org/10.1145/2998181. $\underline{2998234}$

[41] Yousef A M F, Chatti A M, Schroeder U, and Wosnitza M. (2014). What drives a successful MOOC? An empirical examination of criteria to assure design quality of MOOCs. In Advanced Learning Technologies (ICALT), IEEE 14th International Conference on. IEEE, 44-48. https://doi.org/10.1109/ICALT.2014.23

[42] Yousef A M F, Chatti A M, Schroeder U, and Wosnitza M. (2015). A usability evaluation of a blended MOOC environment: An experimental case study. The International Review of Research in Open and Distributed Learning 16, 2 .https://doi.org/10.1 9173/irrodl.v16i2.2032

[43] Zawacki-Richter O, Bozkurt A, Alturki U, and Aldraiweesh A. (2018). What Research Says About MOOCs âĂŞ An Explorative Content Analysis. The International Review of Research in Open and Distributed Learning 19, 1. https://doi.org/10.19 173/irrodl.v19i1.3356

[44] Zheng S, Rosson M B, Shih P C, and Carroll J M. (2015). Designing MOOCs as interactive places for collaborative learning. In Proceedings of the Second ACM Conference on Learning@ Scale. ACM, 343-346. https://doi.org/10.1145/2724660.2728689

[45] Zimmerman T D. (2012). Exploring learner to content interaction as a success factor in online courses. The International Review of Research in Open and Distributed Learning 13, 4, 152-165. https://doi.org/10.19173/irrodl.v13i4.1302

[46] Kersten, S. (2018)."Approaches of engineering pedagogy to improve the quality of teaching in engineering education." In Vocational Teacher Education in Central Asia, pp. 129139. Springer, Cham. https://doi.org/10.1007/978-3-319-73093-6 14

[47] Sajid I, Zang X, Zhu Y, Chen Y, and Zhao J. (2014), "On the impact of MOOCs on engineering education." In 2014 IEEE International Conference on MOOC, Innovation and Technology in Education (MITE), pp. 101-104. IEEE.

[48] Phatak, D B. (2015) "Adopting MOOCs for quality engineering education in India." In Proceedings of the International Conference on Transformations in Engineering Education, pp. 11-23. Springer, New Delhi, 2015. https://doi.org/10.1007/978-81-322-1931-6_3

[49] Gamage, D, Perera I, and Fernando S. (2015) "A Framework to analyze effectiveness of eLearning in MOOC: Learners perspective." In 2015 8th International Conference on UbiMedia Computing (UMEDIA), pp. 236-241. IEEE. https://doi.org/10.11 09/UMEDIA.2015.7297461 
[50] Gamage D, Framework for evaluation MOOCs Survey Instrument, The Github repository, Sept 6, 2016. Accessed on: Sept, 2019. [Online]. Available:https://github.com/iceLearn/ Improving-effectiveness-of-MOOC-my-PhD-research/blob/master/Evalauting\%20effectiveness \%20of\%20MOOCs\%20-\%20Tool\%20u nder $\% 20$ creative $\% 20$ commons $\% 20$ licencse.pdf

\section{$7 \quad$ Authors}

Dilrukshi Gamage is member of the Institute of Electrical and Electronic Engineers (IEEE) association and serve in the executive council since 2017. She is a final year $\mathrm{PhD}$ student at the Department of Computer Science and Engineering in University of Moratuwa, Sri Lanka. Her research area is pedagogical development using technology and Human Computer Interactions. She has been reviewer for top tier journals (Computers and Educations) and published and reviewed in many conferences (TALE, ECUCON, ICALT, CHI, CSCW).

Indika Perera is a senior lecturer at the University of Moratuwa, Sri Lanka. He holds a PhD (St Andrews, UK) MBS (Colombo), MSc (Moratuwa), PGDBM (Colombo) and B.Sc. Eng. (Hons) (Moratuwa). His research interests include research topics of software architecture, software engineering; technology enhanced learning, UX and immersive environments. He is a Fellow of HEA(UK), MIET, SMIEEE and a Chartered Engineer registered at EC (UK) and IE(SL).

Shantha Fernando is a Senior Lecturer at the Department of Computer Science and Engineering, University of Moratuwa, Sri Lanka. He served as the Director, Centre for IT Services, University of Moratuwa. and the Director, Engineering Research Unit, University of Moratuwa. He is one of the founders and the Chief Advisor of TechCERT, affiliated to LK-Domain Registry. His PhD was obtained from the Delft University of Technology, The Netherlands in 2010. His expertise are in Computer and Information Security, Information Systems, and e-Learning.

Article submitted 2019-10-17. Resubmitted 2020-01-01. Final acceptance 2020-01-03. Final version published as submitted by the authors. 